\title{
Spatial distribution of dominant ions in the groundwater in Banyumudal Groundwater Basin, Central Java, Indonesia
}

\author{
Setyawan Purnama ${ }^{1, *}$ \\ ${ }^{1}$ Faculty of Geography, Universitas Gadjah Mada, Indonesia
}

\begin{abstract}
Groundwater basin is an area with hydrogeological limits where it is happened all of hydrogeological processes. Banyumudal Groundwater Basin is one of groundwater basin with unique characteristic because of receiving water source from surroundings area, that would influence probably to the water quality. This study was conducted to: (1) know the spatial distribution of dominant ions concentration in the groundwater; (2) analyze surroundings factors that influence the spatial distribution of dominant ions in the groundwater. To realize the objectives, it was carried out the removal of groundwater samples in the observational wells that were determined by purposive sampling. The analyzed elements were $\mathrm{Ca}^{2+}, \mathrm{Mg}^{2+}, \mathrm{Na}^{+}, \mathrm{K}^{+}, \mathrm{SO}_{4}{ }^{2-}, \mathrm{HCO}_{3-}, \mathrm{CO}_{3}{ }^{2-}, \mathrm{Cl}^{-}$and $\mathrm{Fe}^{2+}$. The concentration of the dominant ions was realized in the form of Stiff Diagram and then was plotted in a map, so that it could be known the distribution. To analyze the process of mixing between the groundwater and water from the other sources with different chemical characteristics, it used the Piper Diagram, whereas to analyze the surroundings effects to the ionic concentration, it was conducted the analysis of quantitative descriptive. The study results showed that the groundwater from the northern part of Banyumudal Groundwater Basin has higher concentration of dominant ions compared with the southern ones. Viewed from each ion, the ionic concentration of $\mathrm{Ca}^{2+}$ and $\mathrm{HCO}_{3-}$ are higher than other dominant ions and have more varied values, so that the change of chemical characteristics of the groundwater would tend to be determined by the concentration change of them. Type of rocks is the most influencing factor to the concentration of dominant ions in the study area. Nevertheless, the domestic waste has also little effects related to the sanitary condition in around of samples location of the groundwater.
\end{abstract}

\section{Introduction}

Water is one of important resources for human life and other living things. Even, according to Fetter (1988) [1] and Purnama (2007) [2], water is the elixir of life, without it life is not possible. Water is also one of the few substances that can be found in all three states (i.e. gas, liquid and solid) within the earth's climatic range [3]. Generally, in daily life water is acquired from four sources, such as ; river, lake or well, groundwater, and rain. Because it is cleaner, the groundwater is used more often as drinking water of people compared than the others.

According to Preeja et al. (2011) [4], groundwater is one of the most valuable natural resources, which supports human health, economic development and ecological diversity. It can be says that groundwater is an important source of water supply throughout the world [5].

Groundwater is a dynamic and replenishing natural resources [6]. Groundwater resources are dynamics in nature and affected by such factors as the expansion of irrigation activities, industrialization, hence monitoring and conserving this important resource is essential [7].

Nonetheless, it was found in recently times phenomena of decreased quality of the groundwater, indicated by contamination of feces that is happened often in some regions [8]. Furthermore, it needs to perform groundwater management in order to always get water in sufficient quantity and with the quality that is adequate to the health requirements. Sustainable management and development of water resources is a major issue all over the word [9].

According to the Government Regulation of Republic of Indonesia Number 43 Year of 2008 [10] concerning about groundwater, the management of groundwater is effort of planning, performing, monitoring, evaluating the implementation of groundwater conservation, groundwater empowerment, and controlling the groundwater damages. In the water resources management, aspect of quality also needs to be considered.

Chemically, the water chemical concentration is not always same among locations, depending on the natural and artificial factors that influence to the water in the concerned locations [11]. The natural factors consist of climate, rocks, and vegetations, whereas artificial factors are fertilizer and agricultural wastes, insecticide, domestic and industrial wastes.

In groundwater, rock is the influencing natural aspect to the chemical characteristics. Each rock has separated composition of mineralogy that would influence the inside chemical characteristics of groundwater. According to Todd \& Mays (2005) [12], the igneous

\footnotetext{
Corresponding author: setyapurna@geo.ugm.ac.id
} 
rock are source of calcium minerals (mineral of silicate, pyroxine, amphibol dan feldspar), magnesium (mineral of olivine, pyroxine, amphibol and mica), sodium, potassium (mineral of feldspar, ortoclase, microlite, mica and feldspatoide), chloride (mineral of felspatoide sodalite, phosphate dan apatite), sulphate (mineral of feldspatoide), silica, iron and manganese (mineral of pyroxine, magnetite, pirite and mineral of clay). The sediment rock is source of elements of natrium, chloride (mineral of evaporite) and sulfate (mineral of gypsume, anhidrite and barite). Base on the background, the objectives of the research were to know the spatial distribution of dominant ions concentration in the groundwater and to analyze surroundings factors that influence the spatial distribution of dominant ions in the groundwater. The choosen location was in Bayumudal Groundwater Basin, because the condition of the basin was still natural.

\section{Methods}

This research needed urgently primary data of chemical concentration data of the groundwater. Furthermore, it was conducted the removal of groundwater samples from observational wells. The determination of observational wells was performed using purposive sampling by considering condition of the rock, flow direction of groundwater, and population density.

Then, it was conducted analysis of the characteristics to know the water chemistry in Laboratory of Hydrology and Environmental Climatology, Faculty of Geography, Universitas Gadjah Mada, Yogyakarta. The analyzed chemical characteristics were $\mathrm{Ca}^{2+}, \mathrm{Mg}^{2+}, \mathrm{Na}^{+}, \mathrm{K}^{+}, \mathrm{SO}_{4}^{2-}$ , $\mathrm{HCO}_{3-}, \mathrm{CO}_{3}{ }^{2-}, \mathrm{Cl}^{-}, \mathrm{Fe}^{2+}$. Parameter of $\mathrm{pH}$ was directly measured in the field.

Besides by looking directly for each ion, distribution analysis of dominant ions was also considered the distribution for all dominant ions simultaneously. Therefore, it used Stiff Diagram and Piper Diagram. Stiff Diagram of each groundwater sample could be analyzed based on form and size. The different form of Stiff Diagram would describe the difference of water chemistry type, whereas the different size would describe the concentration of dominant ions. If it was relatively consistent the form and size of the diagram, it meant that there was not any change of chemical characteristics of groundwater among locations [13].

In Stiff Diagram, the magnitude of dominant ions concentration is described at axis made in right and left directions from the centre, with the unit of chemical concentration of groundwater in miliequivalent per litre (meq/L). Concentration of cation is described to left direction from the axis, whereas anion is described to right direction from the axis. By connecting the ends of axis that connects the ionic concentration, it would be acquired the form and size of specific Stiff Diagram for each sample. Then, it was conducted analysis based on the location at map, so that it get path of dominant ions concentration of groundwater in the area of research.

Piper Diagram is used to analyze mixing process of groundwater with water from other sources in study area.
The concentration of cation and anion are expressed in form of percentage to total amount of ionic concentration, and then plotted in diagram of equilateral triangle. It is withdrawn upwards line from points of the results of plotted cation and anion by referring the most outer side of triangle until there is an intersection. The plotting process was conducted in all samples of groundwater, so that it could be known location, form, and area of the collected points of sample.

Then, it was conducted analysis of quantitative descriptive to know the influence of environment to the ionic concentration, whereas to know the appropriateness of groundwater as source of drinking water, the concentration of dominant ions must be compared with standard quality of water as drinking water.

\section{Results and discussions}

\subsection{Spatial distribution of each dominant ion}

The analysis results of water samples in laboratory showed that concentration of dominant ions in groundwater in research area was varied. Nevertheless, in general, bicarbonate ion has the higher concentration than the others, followed by calcium, sodium, chloride, sulphate, potassium, iron, magnesium, and carbonate. The analysis results of dominant ions could be seen completely in Table 1.

Regarding Table 1, groundwater in the research area has the lowest concentration of calcium $113.0 \mathrm{mg} / \mathrm{L}$, the highest was $253.1 \mathrm{mg} / \mathrm{L}$, with the average of calcium concentration was $157.71 \mathrm{mg} / \mathrm{L}$. According to Todd \& Mays (2005) [12], the calcium concentration in groundwater that is higher than $100 \mathrm{mg} / \mathrm{L}$ is already high. For magnesium, it showed that all samples of groundwater in the research area had a magnesium concentration of $0 \mathrm{mg} / \mathrm{L}$.

Viewed from the distribution, groundwater with a low concentration of calcium was found generally in northern part of the study area, whereas the others with medium and high concentration were found generally in central and southern part or research area. Regarding this spreading path, it could be said that type of rock has highly influenced to the calcium concentration in groundwater. As it was known, the northern part of study area was Halang Formation that consisted of the conjoint of sandstone, claystone, napal and tuff with breccia insertion, whereas in southern part was that consisted of coral limestone, clastic limestone, claystone, shale, and sandstone. The main source of calcium is the dissolution of limestone. 
Table 1. Analysis results of dominant ions in groundwater.

\begin{tabular}{|c|c|c|c|c|c|c|c|c|c|}
\hline $\begin{array}{c}\text { Number of } \\
\text { sample }\end{array}$ & $\begin{array}{c}\text { Calcium } \\
(\mathrm{mg} / \mathrm{L})\end{array}$ & $\begin{array}{c}\text { Magnesium } \\
(\mathrm{mg} / \mathrm{L})\end{array}$ & $\begin{array}{l}\text { Sodium } \\
(\mathrm{mg} / \mathrm{L})\end{array}$ & $\begin{array}{c}\text { Potassium } \\
(\mathrm{mg} / \mathrm{L})\end{array}$ & $\begin{array}{c}\text { Sulphate } \\
(\mathrm{mg} / \mathrm{L})\end{array}$ & $\begin{array}{c}\text { Bicarbonate } \\
(\mathrm{mg} / \mathrm{L})\end{array}$ & $\begin{array}{c}\text { Carbonate } \\
(\mathrm{mg} / \mathrm{L})\end{array}$ & $\begin{array}{c}\text { Chloride } \\
(\mathrm{mg} / \mathrm{L})\end{array}$ & $\begin{array}{c}\text { Iron } \\
(\mathrm{mg} / \mathrm{L})\end{array}$ \\
\hline 1 & 199.9 & 0 & 48.5 & 5.9 & 16.8 & 603 & 0 & 60 & 0.78 \\
\hline 2 & 117.5 & 0 & 108.9 & 4.5 & 8.4 & 424 & 0 & 22 & 1.03 \\
\hline 3 & 194.3 & 0 & 105.2 & 4.2 & 23.0 & 823 & 0 & 68 & 0.20 \\
\hline 4 & 167.2 & 0 & 19.3 & 4.3 & 3.0 & 636 & 0 & 22 & 0.34 \\
\hline 5 & 103.9 & 0 & 183.7 & 3.7 & 8.3 & 372 & 0 & 16 & 0.57 \\
\hline 6 & 117.5 & 0 & 13.5 & 1.8 & 12.2 & 360 & 0 & 14 & 1.03 \\
\hline 7 & 203.4 & 0 & 0.7 & 7.2 & 9.8 & 647 & 0 & 18 & 0.43 \\
\hline 8 & 153.6 & 0 & 35.8 & 2.5 & 10.7 & 446 & 0 & 16 & 0.61 \\
\hline 9 & 144.6 & 0 & 94.3 & 13.2 & 11.2 & 558 & 0 & 22 & 0.78 \\
\hline 10 & 113.0 & 0 & 49.4 & 31.1 & 24.2 & 383 & 0 & 16 & 0.41 \\
\hline 11 & 113.0 & 0 & 55.1 & 8.5 & 12.3 & 375 & 0 & 28 & 0.43 \\
\hline 12 & 131.0 & 0 & 23.2 & 2.6 & 13.2 & 543 & 0 & 30 & 0.50 \\
\hline 13 & 203.0 & 0 & 29.4 & 9.0 & 17.8 & 814 & 0 & 38 & 0.57 \\
\hline 14 & 153.6 & 0 & 96.4 & 5.0 & 23.3 & 383 & 0 & 60 & 0.78 \\
\hline 15 & 135.6 & 0 & 31.7 & 3.3 & 21.6 & 312 & 0 & 30 & 0.61 \\
\hline 16 & 253.1 & 0 & 25.8 & 2.5 & 15.2 & 810 & 0 & 22 & 1.03 \\
\hline 17 & 176.3 & 0 & 45.1 & 7.9 & 20.3 & 535 & 0 & 16 & 0.61 \\
\hline 18 & 158.2 & 0 & 16.5 & 8.1 & 20.3 & 561 & 0 & 28 & 0.78 \\
\hline Average & 157.71 & 0 & 54.58 & 6.96 & 15.09 & 532.50 & 0 & 29.22 & 0.64 \\
\hline
\end{tabular}

Viewed from sodium concentration, groundwater in study area had lowest sodium concentration of 0.70 $\mathrm{mg} / \mathrm{L}$, highest of $183.7 \mathrm{mg} / \mathrm{L}$, and in average of 54.58 $\mathrm{mg} / \mathrm{L}$. Viewed from the distribution, groundwater with low sodium concentration involved most of study area, whereas high sodium concentration was only found in sample of number 5 in eastern part of study area of Banyumudal Groundwater Basin. Regarding to path of distribution, the distribution of sodium concentration in study area was generally quite varied. The concentration of sodium in samples of water was determined by effects of local rock.

Related to potassium, groundwater in study area had lowest potassium concentration of $1.8 \mathrm{mg} / \mathrm{L}$, highest of $31.1 \mathrm{mg} / \mathrm{L}$, and in average of $6.96 \mathrm{mg} / \mathrm{L}$. Viewed from the distribution, groundwater with low natrium concentration was found in the most of study area, whereas medium and high concentration were found only in a sample of number 9 in Rowokele and sample of number 10 in Kretek. The two points of sample were located in central and northern parts of study area.

The sulphate concentration of groundwater in study area still existed in the standard quality. The analysis results in the laboratory showed that the lowest concentration of sulfate was $3.0 \mathrm{mg} / \mathrm{L}$, the highest was $23.3 \mathrm{mg} / \mathrm{L}$, and the average was $15.09 \mathrm{mg} / \mathrm{L}$. Spatially, groundwater with medium and high concentration was found in most of study area. Regarding to path of distribution, sulphate concentration in study area was quite varied. Such as natrium, the concentration of sulphate in samples of water was determined by effects of local rocks.

Bicarbonate and carbonate are dominant ions in freshwater and the compound that caused water basicity. Sources of these two anions in groundwater were limestone, $\mathrm{CaCO}_{3}$ and dolomite, $\mathrm{CaMg}\left(\mathrm{CO}_{3}\right)_{2}$. The analysis results in laboratory showed that the groundwater in study area had the lowest concentration of $312 \mathrm{mg} / \mathrm{L}$, and the highest of $814 \mathrm{mg} / \mathrm{L}$. The average concentration of bicarbonate was $532.50 \mathrm{mg} / \mathrm{L}$. The distribution of bicarbonate in groundwater was varied, so that factor of surrounding environment sample of water had more influenced to the concentration of bicarbonate compared with flow direction of groundwater or type of rocks. All samples of groundwater in study area had carbonate concentration of $0 \mathrm{mg} / \mathrm{L}$.

Related to chloride, the groundwater in study area had lowest chloride concentration of $14 \mathrm{mg} / \mathrm{L}$, highest of $68 \mathrm{mg} / \mathrm{L}$, and average concentration of $29.22 \mathrm{mg} / \mathrm{L}$. Regulation of Minister of Health Republic of Indonesia Number 492 Year 2010 [14] concerning about quality standard of drinking water had required the chloride concentration of $250 \mathrm{mg} / \mathrm{L}$ in water as adequate water for source of drinking water, so that based on this standard of quality, all samples of water were adequate to be consumption. Viewed from distribution, groundwater with low concentration of chloride was found in the most of study area, whereas groundwater with high concentration of chloride were found only in three samples i.e. sample of number 1 in Bumiagung, sample of number 3 in Selokerto, and sample of number 14 in Aseman. The three points of samples were found in central and northern of study area. Based on this description, it could be known that the areas located at the bottom part had higher concentration of chloride than the upper areas. This phenomena was caused by effect of groundwater flow that tend to go from south to north, where during the flowing, it had dissolved the chloride from the rock.

In groundwater, the iron was generally dissolved as ion $\mathrm{Fe}^{2+}$. Although it was not the mostly found element in water, iron was one of important elements in groundwater. The groundwater in study area had the lowest ironic concentration of $0.20 \mathrm{mg} / \mathrm{L}$, highest of 1.03 $\mathrm{mg} / \mathrm{L}$, and average concentration of $0.64 \mathrm{mg} / \mathrm{L}$. Regarding to this data, it could be said that groundwater in study area had high ironic concentration. Regulation of Minister of Health Republic of Indonesia Number 492 Year 2010 [14] concerning about quality standard of drinking water had required the ironic concentration of $0.3 \mathrm{mg} / \mathrm{L}$ in water as adequate water for drinking water, so that almost all of groundwater in study area was not 
adequate to be used as source of drinking water. Groundwater with low concentration of iron could only be found in one water sample i.e. sample of number 3 in Selokerto.

\subsection{Analysis of distribution by Stiff Diagram}

Integratedly, the groundwater chemical characteristics in study area were analyzed by Stiff Diagram. By this diagram, it could be seen fastly the distribution of dominant ions in study area simultaneously. Furthermore, the concentration of dominant ions was needed to be changed the unit, from $\mathrm{mg} / \mathrm{L}$ to be meq/L which the results of calculation could be seen in Table 2 .

Based on the results of this unit change, it was made Stiff Diagram for each sample such as be shown in Figure 1. Figure 1 shows that the form and size of Stiff Diagram had experienced a little difference among locations.
By regarding the large of each diagram, generally the Stiff Diagram in northern and eastern parts of study area had greater size than Stiff Diagram in southern part of study area. It meant that concentration of dominant ions of groundwater in northern part of study area was greater than concentration of dominant ions of groundwater in southern part of study area. In more detail, it was shown the difference that was mainly caused by long of diagram line in central part, that meant that it was caused by the quantity of ionic concentration of calcium and bicarbonate.

Viewed from the form, the form of Stiff Diagram in study area was apparently tended to be uniform, so that the chemical characteristics of groundwater would tend to be same. A little difference of the form was possibly caused by the difference of environmental conditions in around of groundwater samples such as sanitary condition. In general, it could be said that the groundwater condition in study area was still to be natural.

Table 2. Analysis results of dominant ions in groundwater in unit of meq/L

\begin{tabular}{|c|c|c|c|c|c|c|c|c|c|}
\hline $\begin{array}{c}\text { Number of } \\
\text { sample }\end{array}$ & $\begin{array}{l}\text { Calcium } \\
(\mathrm{meq} / \mathrm{L})\end{array}$ & $\begin{array}{c}\text { Magnesium } \\
(\mathrm{meq} / \mathrm{L})\end{array}$ & $\begin{array}{l}\text { Sodium } \\
(\mathrm{meq} / \mathrm{L})\end{array}$ & $\begin{array}{c}\text { Potassium } \\
(\mathrm{meq} / \mathrm{L})\end{array}$ & $\begin{array}{c}\text { Sulphate } \\
(\mathrm{meq} / \mathrm{L})\end{array}$ & $\begin{array}{c}\text { Bicarbonate } \\
(\mathrm{meq} / \mathrm{L})\end{array}$ & $\begin{array}{c}\text { Carbonate } \\
(\mathrm{meq} / \mathrm{L})\end{array}$ & $\begin{array}{l}\text { Chloride } \\
(\mathrm{meq} / \mathrm{L})\end{array}$ & $\begin{array}{c}\text { Iron } \\
(\mathrm{meq} / \mathrm{L})\end{array}$ \\
\hline 1 & 9.97 & 0 & 2.11 & 0.15 & 0.35 & 9.88 & 0 & 1.69 & 0.03 \\
\hline 2 & 5.86 & 0 & 4.74 & 0.12 & 0.17 & 6.95 & 0 & 0.62 & 0.04 \\
\hline 3 & 9.69 & 0 & 4.58 & 0.11 & 0.48 & 13.49 & 0 & 1.92 & 0.01 \\
\hline 4 & 8.34 & 0 & 0.84 & 0.11 & 0.06 & 10.42 & 0 & 0.62 & 0.01 \\
\hline 5 & 5.18 & 0 & 7.99 & 0.10 & 0.17 & 6.10 & 0 & 0.45 & 0.02 \\
\hline 6 & 5.86 & 0 & 0.59 & 0.05 & 0.25 & 5.90 & 0 & 0.39 & 0.04 \\
\hline 7 & 10.15 & 0 & 0.03 & 0.18 & 0.20 & 10.60 & 0 & 0.51 & 0.02 \\
\hline 8 & 7.66 & 0 & 1.56 & 0.06 & 0.22 & 7.31 & 0 & 0.45 & 0.02 \\
\hline 9 & 7.21 & 0 & 4.10 & 0.34 & 0.23 & 9.15 & 0 & 0.62 & 0.03 \\
\hline 10 & 5.64 & 0 & 2.20 & 0.79 & 0.50 & 6.28 & 0 & 0.45 & 0.02 \\
\hline 11 & 5.64 & 0 & 2.40 & 0.22 & 0.26 & 6.15 & 0 & 0.79 & 0.02 \\
\hline 12 & 6.54 & 0 & 1.01 & 0.07 & 0.27 & 8.90 & 0 & 0.15 & 0.02 \\
\hline 13 & 10.13 & 0 & 1.28 & 0.23 & 0.37 & 13.34 & 0 & 1.07 & 0.02 \\
\hline 14 & 7.66 & 0 & 4.19 & 0.13 & 0.48 & 6.28 & 0 & 1.69 & 0.03 \\
\hline 15 & 6.77 & 0 & 1.38 & 0.08 & 0.45 & 5.11 & 0 & 0.15 & 0.02 \\
\hline 16 & 12.63 & 0 & 1.12 & 0.06 & 0.32 & 13.28 & 0 & 0.62 & 0.04 \\
\hline 17 & 8.80 & 0 & 1.96 & 0.18 & 0.42 & 8.77 & 0 & 0.45 & 0.02 \\
\hline 18 & 7.89 & 0 & 0.72 & 0.21 & 0.42 & 9.19 & 0 & 0.79 & 0.03 \\
\hline
\end{tabular}

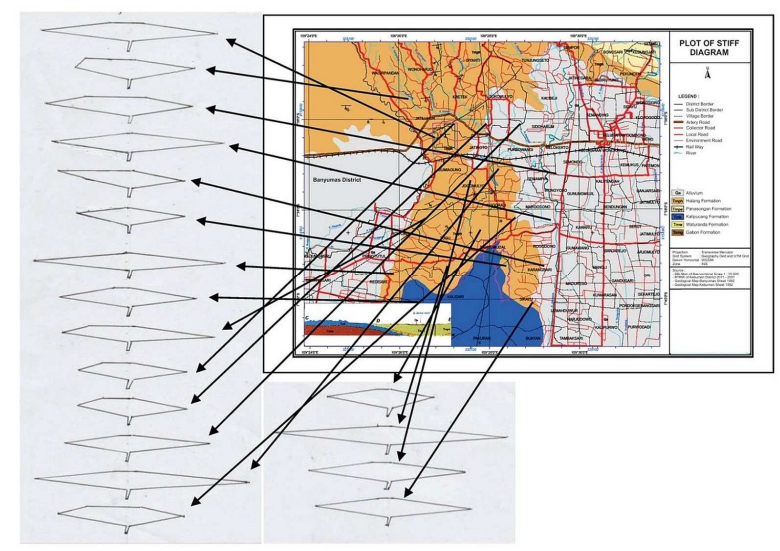

Fig. 1. Plotting results by Stiff Diagram in geological map in the study area 


\subsection{Analysis of dominant ions by Piper Diagram}

In addition to Stiff, there is another method for conducting analysis of groundwater quality, especially for dominant ions in the study area, it is by using Piper Diagram. Basically, Piper Diagram is functioned to know the percentage of certain ions to total ions, both cation and anion that are represented in a diagram of equilateral triangle (Table 3). The plotting results of dominant ions in Piper Diagram could be seen in Figure 2.

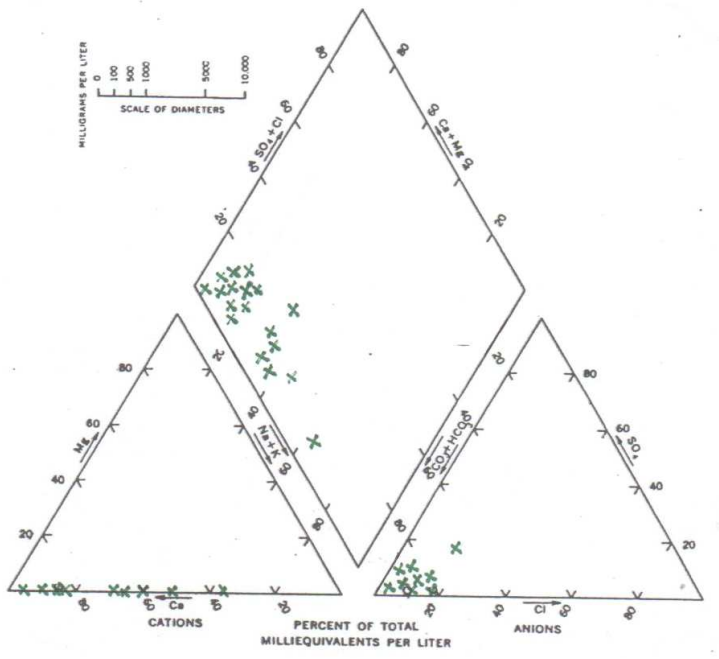

Fig. 2. Plotting of dominant ions in Piper Diagram

It was known from the plotting results of cation in Piper Diagram that the groundwater in the research area had a high concentration of $\mathrm{Ca}^{2+}$. Ion of $\mathrm{Na}^{+}$and $\mathrm{K}^{+}$tend to be clustered and had lower concentration relatively, whereas ion of $\mathrm{Mg}^{2+}$ for all samples has a concentration of $0 \mathrm{mg} / \mathrm{L}$. In anion, ion of $\mathrm{HCO}_{3-}$ had higher and varied value, whereas ion $\mathrm{SO}_{4}{ }^{2-}$ dan $\mathrm{Cl}^{-}$had relatively spreading in the same and low value. Then, the plotting results of cation and anion showed that groundwater in the area of research had a high ionic concentration of $\mathrm{Ca}^{2+}$ dan $\mathrm{HCO}_{3-}$, so that the change of groundwater chemical characteristics would tend to be determined by the change of the high concentration ions.

In Piper Diagram could also be seen that the plotting results tended to be clustered in the form of a straight line. It meant that it was happened water mixing from other sources with different chemical characteristics [15]. The more spread the samples would be acquired more complex of components and mixing processes. In the area of research, the most influencing dominant aspects to the groundwater quality were the type of rock and domestic wastes.

\section{Conclusion}

Analysis of spatial distribution of dominant ions in the groundwater by Stiff Diagram showed that visually the size of Stiff Diagram in northern part of Banyumudal Groundwater Basin was greater than the size of Stiff
Diagram in central and southern part of Banyumudal Groundwater Basin. That meant that the groundwater in northern part of Banyumudal Groundwater Basin has higher concentration of total dominant ions $\left(\mathrm{Ca}^{2+}, \mathrm{Mg}^{2+}\right.$, $\mathrm{Na}^{+}, \mathrm{K}^{+}, \mathrm{Cl}^{-}, \mathrm{SO}_{4}{ }^{2-}, \mathrm{HCO}_{3-}$ and $\mathrm{CO}_{3-}$ ).

Analysis of spatial distribution by Piper Diagram showed that the groundwater in research area has higher ionic concentration of $\mathrm{Ca}^{2+}$ and $\mathrm{HCO}_{3-}$ than other dominant ions and the value was more varied, so that the change of chemical characteristics of the groundwater in study area would tend to be determined by the ionic concentration change.

Related to the standard quality of water, except for sample of number 3 in Selokarto, the ionic concentration of iron in all samples of groundwater in the research area has exceeded the standard quality of water as drinking water based on Regulation of Minister of Health of RI Number 492/Menkes/Per/IV/2010.

Type of rocks is the most influencing factor to the concentration dominant ions in study area. Nevertheless, the domestic waste has also little effects related to the sanitary condition in around of samples location of the groundwater.

This article is a part of research related to the quality of groundwater in Banyumudal Groundwater Basin that was fund by BOPTN Faculty of Geography UGM in 2017.

\section{References}

1. C. W. Fetter, C. W. Applied hydrogeology. Merrill Publishing Company, Columbus-Ohio (1988)

2. S. Purnama. Groundwater pollution model in Yogyakarta City. Majalah Geografi Indonesia 21 (2): 124-145 (2007)

3. T. Davie. Fundamentals of hydrology. Routledge, Taylor \& Francis Group, London (2008)

4. K. R. Preeja, S. Joseph, J. Thomas, H. Vijith. Identification of groundwater potential zones of a Tropical River Basin (Kerala, India) using remote sensing and GIS techniques. J. Indian Soc. Remote Sens (2011)

5. R. S. S. Rose, N. Krisnan. Spatial analysis of groundwater potential using remote sensing and GIS in The Kanyakumari and Nambiyar Basins, India. J. Indian Soc. Remote Sens 37: 681-692 (2009)

6. M. Nagarajan, S. Singh, S. Assessment of potential groundwater zones using GIS technique. J. Indian Soc. Remote Sens 37: 69-77 (2009)

7. R. Chatterjee. Groundwater quality assessment of Dhanbad District, Jharkhand, India. Bull Eng Environ 69: 137-141 (2009)

8. S. Purnama. Hidrologi air tanah. Penerbit Kanisius, Yogyakarta (2010)

9. I. S. Al-Salamah, Y. M. Ghazaw, A. R. Ghumman, A. R. Groundwater modeling of Saq Aquifer Buraydal Al Qassim for better water management 
strategies. Environ Monit Assess 173: 851-860 (2011)

10. Government Regulation of Republic of Indonesia Number 43 Year of 2008 concerning about groundwater

11. J. D. Hem, J. D. Study and interpretation of the chemical characteristics of natural water. United States Government Printing Office, Washington (1970)

12. D. K. Todd, L. W. Mays L.W. Groundwater hydrology. John Wiley \& Sons, New York (2005)

13. S. Purnama. Quality and chemistry types of groundwater in coastal area of Semarang City. Forum Geografi 18 (2): 134-151 (2004)

14. Regulation of Minister of Health Republic of Indonesia Number 492 Year 2010 concerning about quality standard of drinking water

15. S. N. Davis, R. J. M. de Weist. Hydrogeology. John Wiley and Sons, New York (1966) 